\title{
La transversalidad en la investigación de la Historia del Arte
}

\author{
Esther MERINO \\ Dpto. de Historia del Arte II (Moderno). Universidad Complutense de Madrid
}

A la hora de hacer la presentación de la sexta sesión de estos encuentros de jóvenes investigadores, dedicada a las Fuentes y la Metodología, era mi intención aportar mi experiencia en la colaboración con un Grupo de investigación sobre Cartografía junto a una línea de investigación particular, que en los últimos años está enfocada a la Historia del Espectáculo, la Historia de la Escenografía y las Artes Escénicas. Temas aparentemente divergentes, que sin embargo, comparten la misma problemática en cuanto a la dificultad de accesibilidad y cuya mejor comprensión se extrae en la confluencia interdisciplinar derivada de un enfoque más integrador de las materias que componen la Historia del Arte.

Explicando el propósito y el sentido mismo del Instituto de Humanidades, decía Ortega que para emprender el estudio y la investigación de las distintas dimensiones que conforman la vida humana, había que buscar "amplia colaboración", para renovar las tradicionales disciplinas históricas, y que dichas Humanidades se abrieran a nuevas perspectivas, aunque esto exigiera un mayor esfuerzo intelectual, en el marco de algo que él definió como "observación masiva"1.

El enfoque transversal de las distintas materias permite acometer la investigación de los distintos temas desde un punto de vista multidisciplinar, con una perspectiva más amplia y enriquecedora, gracias a la cual las conclusiones son más completas, implicando aspectos más diversos que aquéllos derivados de monografías más acotadas, recortadas, monofocales, si se permite la expresión. En definitiva, la adopción de ese punto de vista en la investigación de la Historia del Arte viene a hacer realidad el sueño visionario de Leonardo del Parangón de las Artes, la "ut pictura poesis" llevada a la máxima expresión y recuperada para la Historiografía por la Escuela de Aby Warburg, las nuevas visiones de viejos maestros de Gombrich y las amplias perspectivas de Panofsky.

1 ORTEGA Y GASSET, José, Obras Completas, t. VII, Madrid, 1969, p. 19. 
Así son más lógicos los planteamientos en la superación de limitaciones metodológicas, a la hora de afrontar una parte sustancial del Patrimonio artístico, desde la carpintería de armar a las fuentes literarias y propuestas alternativas entre las que se incluyen los estudios sobre la Historia de la Educación a través de la pintura costumbrista o de género, o la multiculturalidad aprehensible en los distintos festejos conmemorativos de lo que puede conformar la Historia del Espectáculo y las Artes Escénicas.

Específicamente, en mi caso, dicho enfoque se ha traducido en los últimos años formando parte de un Grupo de Investigación sobre Cartografía ${ }^{2}$, en el que también participan Arquitectos de Expresión Gráfica, de Composición e Ingenieros Técnicos de distintas Universidades, encarando la materia de análisis desde perspectivas distintas, técnicas y artísticas, pero complementarias, siendo el objeto de la investigación en concreto la Forma de Representación del Territorio y su Evolución Histórica.

El objetivo de los distintos proyectos en proceso conlleva el establecimiento de una metodología para gestionar con criterios de sostenibilidad los recursos patrimoniales de los territorios acotados en los diferentes trabajos, que abarcan todo tipo de representaciones iconográficas de Península Ibérica y el continente americano, así como aquéllas derivadas de distintas expediciones científicas. Una labor que se ha centrado en la búsqueda de documentos cartográficos entre los fondos del Archivo General de Simancas (Valladolid), el Archivo Histórico Nacional (Madrid), la Real Chancillería (Valladolid), la Biblioteca Nacional de España, el Instituto Geográfico Nacional (Madrid), el Centro Geográfico del Ejército (Madrid), la Biblioteca de Estudios de la Universidad de Salamanca, la Biblioteca el Palacio Real (Madrid), el Museo Marítimo del Cantábrico (Santander) o el Archivo General Militar (Madrid), entre otros.

Dichos proyectos, asimismo, cumplen los preceptos del llamado Programa Marco establecido por el Ministerio de Ciencia e Innovación, para que las actividades de los I+D+I estén al servicio de los ciudadanos, canalizándose la transferencia del conocimiento a la sociedad, mediante la exposición pública de resultados, a través de la Semana de la Ciencia de Madrid y elaborando una base de datos cartográfica y bibliográfica ${ }^{3}$ específica, cuya consulta fuera accesible a

2 CHÍAS NAVARRO, Pilar y ABAD BALBOA, Tomás, "Las vías de comunicación en la cartografía histórica de la Cuenca del Duero: construcción del territorio y paisaje”, en Ingeniería Civil, 149, 2008, pp. $1-24$.

HARLEY, J. B., La nueva naturaleza de los mapas: ensayos sobre la historia de la cartografia, México, 2005; CHÍAS, P., "La caligrafía de Mercator y otras singularidades de la rotulación de mapas", en Revista EGA, 13, 2008, pp. 34-49; GOSS, J., Ciudades de Europa y España. Mapas antiguos del siglo XVI de Braun y Hogenberg, Libsa, Madrid, 1992; Instituto Geográfico Nacional, Fondos cartográficos del Instituto Geográfico Nacional. Siglos XVI-XIX, IGN, Madrid, 2000; GUTIÉRREZ, R. y ESTERAS, C., Territorio y Fortificación. Vauban, Fernández de Medrano, Ignacio Sala y Félix Prósperi. Influencia en España y América, Madrid, 1991; LÍTER MAYAYO, M., SANCHÍS BALLESTER, F., y HERRERO VIGIL, A., Cartogra- 
otros investigadores. Se trata de hacer más asequibles y funcionales los recursos documentales e históricos, para innovar y crear sobre la base de la propia singularidad territorial y posibilitar la integración de toda la información resultante, en un sistema operativo de información geográfica mediante la colaboración de investigadores de disciplinas distintas de las Ciencias y las Artes Humanísticas, con la pretensión, en definitiva, de dotar de instrumentos de conocimiento, de perspectiva artística y de gestión a las Administraciones Públicas, para mejorar el nivel de vida de los habitantes de las distintas comunidades que se han mostrado interesadas en adscribirse al proyecto, financiándolo, sobre la base de la difusión e impulso de los recursos patrimoniales para fomentar su desarrollo siguiendo criterios de sostenibilidad.

Por otra parte, el acceso a los Archivos en Red y los grandes avances en la digitalización han facilitado la investigación en casi todas las materias, aunque a la postre resulte insustituible la consulta directa para dilucidar marcas de agua, anotaciones e incluso la nítida percepción del cromatismo de los originales.

La Cartografía constituye uno de los mejores exponentes de la conjunción de Ciencia y Estética. Así, la investigación histórica se erige en base imprescindible de conocimientos, previa a la intervención científica y pragmática. Pretensión al fin y al cabo que retoma los postulados del pasado e incluso la metodología de las nuevas tecnologías parte del análisis de las Fuentes Historiográficas. Hipodamos, Dinócrates, Vitruvio, Ptolomeo, Estrabón, las guías medievales para visitar Relicarios, la Ciudad de Dios, las Utopías, las Galerías de Mapas, la Fortificación del Baluarte como mentalidad, la expansión europea, los Libros de Viajes y el Colonialismo tanto como el género pictórico del Paisaje, los nuevos materiales y la Ciudad Industrial, los Diccionarios Geográficos, los Mapas Geológicos, hasta el Catastro, se erigen en consustanciales elementos, imprescindibles para comprender la evolución histórica en la representación cartográfica.

Con el tiempo fue imponiéndose la percepción sensorial tridimensional del espacio, de la ubicación geográfica, topográfica y urbana, que era a juicio de Kant "una forma pura de intuición" " a la que habría que sumar, además, la referencia simbólica, de todo lo cual se deduce lo que algunos han denominado el "espacio poético". Por tanto, el análisis de la evolución histórica del territorio y del paisaje debía ser abordado desde diferentes ámbitos, arquitectónico, urbano y territorial, desde la revisión de las fuentes documentales pero también desde la interpretación de las fuentes gráficas: cartográficas, dibujos, cuadros y fotografías incluso, con las

fia de España en la Biblioteca Nacional. Siglos XVI al XIX, Madrid, 1994; de SETA, C. (ed.), Cittá d'Europa. Iconografia e Vedutismo dal XV al XIX secolo, Nápoles, 1996.

4 DELFANTE, Charles, Gran Historia de la Ciudad, Madrid, 2006, p. 18 


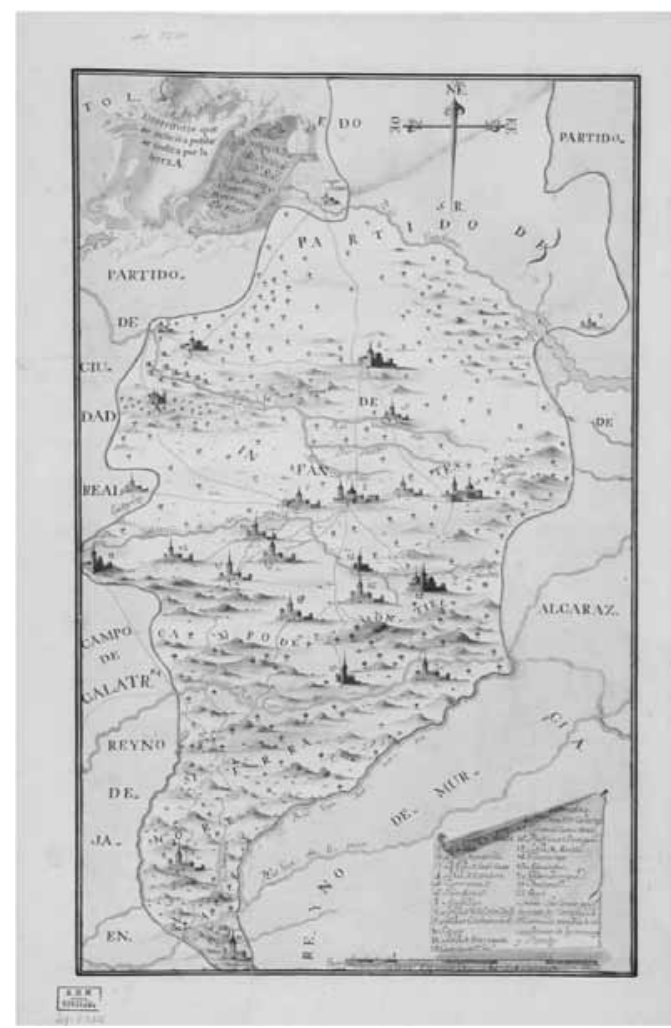

Fig. 1. Archivo Histórico Nacional

consiguientes dificultades inherentes a la localización de los fondos y acceso a los mismos (fig. 1).

Sondeos analíticos y metáforas forman parte de visiones más amplias en la investigación del gran archivo de la herencia histórica dentro de lo que se ha denominado "cultura del lugar y del habitar". . El estudio de la tradición gráfica permite además una mayor comprensión del "espacio vivo", desde su génesis histórica, las posibilidades estéticas de la propia representación, como también aquéllas ideológicas y semánticas $^{6}$, que ayudan a descifrar el programa iconológico que impregna en cada estadio temporal la imagen y la cartografía no escapa a esta posible percepción (fig. 2 y 3 ).

Si mayores son las dificultades para investigar asuntos desde planteamientos más amplios, que impliquen establecer estudios comparativos y de amplio espectro, aún con los inventarios actualizados y digitalizados, hay materias que no están reunidas en una catalogación integral de manera que la misma búsqueda se convierte en una carrera de obstáculos. En el caso de la localización de iconografía cartográfica en el Archivo Histórico Nacional, esto supone la revisión de todos los fondos diversos encuadrados tanto en Inventarios de Pleitos Inquisitoriales, como de Órdenes Militares, del Consejo de Estado o del Archivo Secreto.

En lo que a la Escenografía se refiere, en mi línea de investigación personal de los últimos tiempos, las dificultades aumentan si cabe, habiéndose de plantear búsquedas colaterales, a través de los Grabadores de las estampas de los Libretos de Festejos o representaciones teatrales, si es que éstos existieron y que además se conserven. Por tanto, es necesario afrontar la localización y el análisis desde la transversalidad de asuntos que conforman la Historia del Espectáculo: Arte Efímero, Arquitectura, Pintura, Artes Aplicadas, Historia del Jardín y del Urbanismo,

\footnotetext{
5 GRAVAGNOLO, Benedetto, Historia del Urbanismo en Europa, 1750-1960, Madrid, 2000, pp. 8-9.
}

6 BRAUNFELS, Wolfgang, Urbanismo occidental, Madrid, 1987, pp. 13-17. 
además de las propias Fuentes Documentales y Bibliográficas.

Porque la Escenografía abarcaba en la época moderna decoración teatral, de festivales y aquéllas ornamentaciones concebidas para celebrar exequias fúnebres, entradas triunfales, justas, ballets ecuestres y mascaradas. En ese contexto de producción artística efímera, se concibió el género operístico y las coreografias, $y$, sin duda alguna, las puestas en escena más espectaculares del Barroco. En muchas ocasiones, se puede acceder al conocimiento de lo que fueron semejantes eventos, a través de testimonios visuales, estampas, o escritos, libretos, en los que se dejaba constancia de la suntuosidad y la dificultad conceptual escondidos tras las imágenes. La iconología de la iconografía festiva, a menudo recopilaciones concebidas igualmente como amuletos u obsequios para los asistentes privilegiados (fig. 3).

Por si fuera poco, fundamentalmente durante el siglo XVII, terminó de definirse la

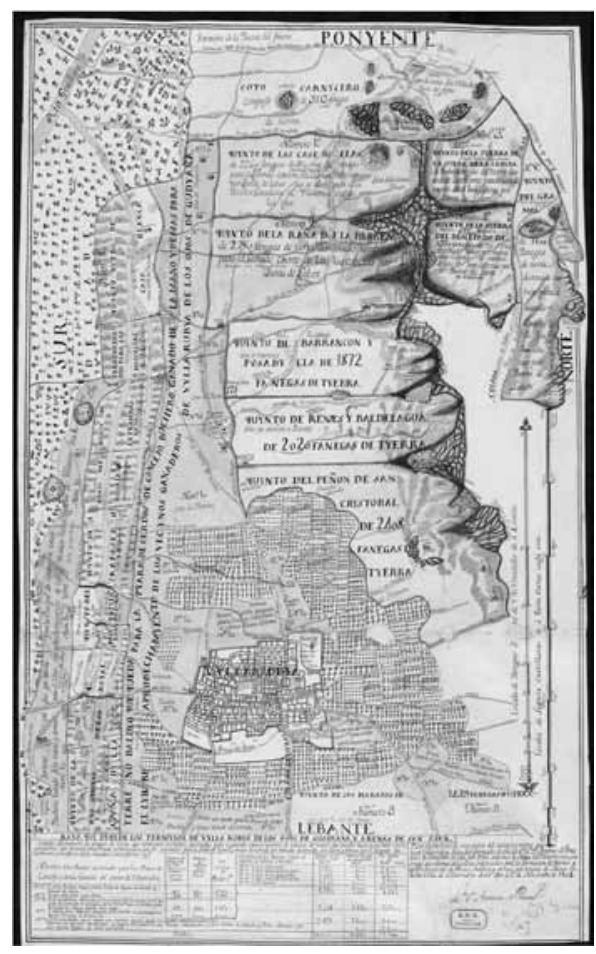

Fig. 2. Archivo Histórico Nacional figura del Escenógrafo profesional, el genuino representante del artista polifacético, gracias a sus diversos y dispares conocimientos: tanto de ingeniería, maquinaria y aparatos, como de arquitectura, diseño urbano, pero también literario, para poder revisar e incluso elaborar la redacción de los libretos, así como formación técnica más que suficiente para tener "suspendidos" a los espectadores con todo tipo de sorpresas, conocimientos de artillería para diseñar complejos programas pirotécnicos, así como experiencia de carácter puramente teatral para idear y construir los decorados efímeros o la propia "caja" del edificio escénico. No sólo todo ello, sino habilidades para dominar la teoría y la práctica de la perspectiva inherente para enmarcar las representaciones dentro de los parámetros de la "ventana albertiana", discurriendo la práctica escenográfica hasta desembocar en un deleite obsesivo por las composiciones de perspectivas extremas hasta el infinito y la multiplicidad focal. Y, junto a todo ello, nociones más que notables de música para poder dirigir coreografías de grandes masas de estos espectáculos globales de implícita teatralidad, en que termina convirtiéndose la denominada Fiesta Barroca, como "instrumentum regni".

Fue, en definitiva, en los distintos entornos de los señores del Cinquecento, en los que encontraron especial acomodo espiritual todos los elementos definitorios del es- 


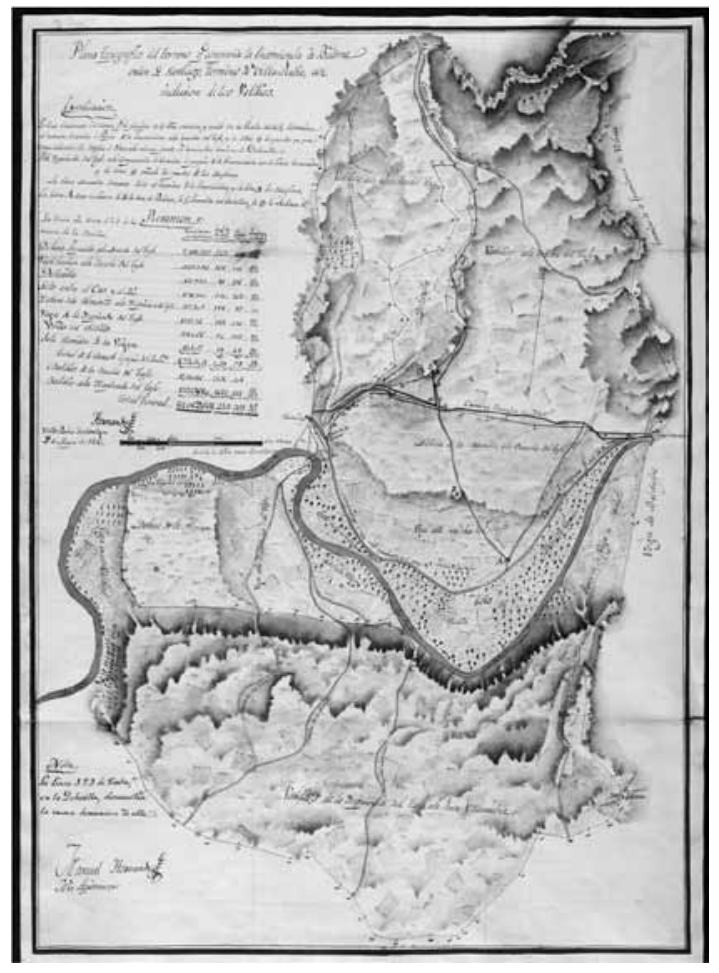

Fig. 3. Archivo Histórico Nacional pectáculo cortesano, con la finalidad preeminente de la propaganda política $^{7}$ y glorificación dinástica de universalidad normativa. El arte del espectáculo se fue convirtiendo en "la sublimazione triúnfale d'ogni attivitá cittadina" ${ }^{8}$, razón por la cual reyes y señores quisieron participar como actores principales, intérpretes naturales de su escenario predilecto y sacralizado. La Corte del temprano Barroco en Florencia era ya en sí mismo un organismo teatral. Con la etiqueta cortesana devino la regularización sistemática de reglas y herramientas del espectáculo 9 . Algunos lo han denominado la "cristalización de una inteligencia" sutil en la creación de la mentalidad y el lenguaje propiamente cortesano. Es en este ámbito especulativo y creativo en el cual el Escenógrafo cobra amplias dimensiones como representante del artista global y polifacético de la era moderna, en el que se hizo realidad el parangón

7 Como tan claramente expuso José Antonio MARAVALL, en "La literatura de emblemas", Teatro y Literatura en la sociedad barroca, Barcelona, 1990, pp. 113 y 186, "Era común opinión en el siglo XVII que con la artística disposición de la verdad, era más fácil atraer la voluntad del hombre hacia ella". Abundando en esta idea, fundamental para la semiótica del espectáculo barroco, decía Maravall que "el teatro poseía unas condiciones especiales en la transmisión sumamente dinámica del mensaje de sumisión al orden estamental establecido", frente a discrepancias que iban surgiendo en el seno de la Monarquía Hispana, y que condujeron a las revueltas portuguesas y catalanas. "Porque si a todas las artes visuales les era común la capacidad de impresionar el ánimo y mover la voluntad, ninguna tenía en esto la fuerza tan considerable de la representación escénica. En la escena pues, se desarrollaba con un propósito doctrinario, por la vía emotiva, una acción que ponía al descubierto la grandeza de la persona del rey y de la legitimidad de la sociedad jerárquica que éste presidia". Ver también, del mismo autor Teatro y literatura en la sociedad barroca, Madrid, 1986.

GARBERO ZORZI, E. y SPERENZI, M., Teatro e spettacolo nella Firenze dei Medici: modelli dei luoghi teatrali, catálogo de la exposición (Florencia, 2001), Florencia, 2001, p. 266.

9 “... perseguono una propia politica celebrativa e di rappresentanza, sviluppano una sequenza specifica e riconoscible di eventi spettacolari, instaurano un'organizzazione propia per diversi generi di manifestazioni...letteralmente si mette in scena, espone se stessa e la sua storia in un'azione spettacolare di propaganda...", 3. Feste civile e instituzioni comunali, "Festa e spettacolo in Italia nel secolo della Controriforma", CARANDINI, Silvia, Teatro e spettacolo nel Seicento, e spettacolo nel Seicento, Roma, 1995, cap. II, pp. 45-46. 


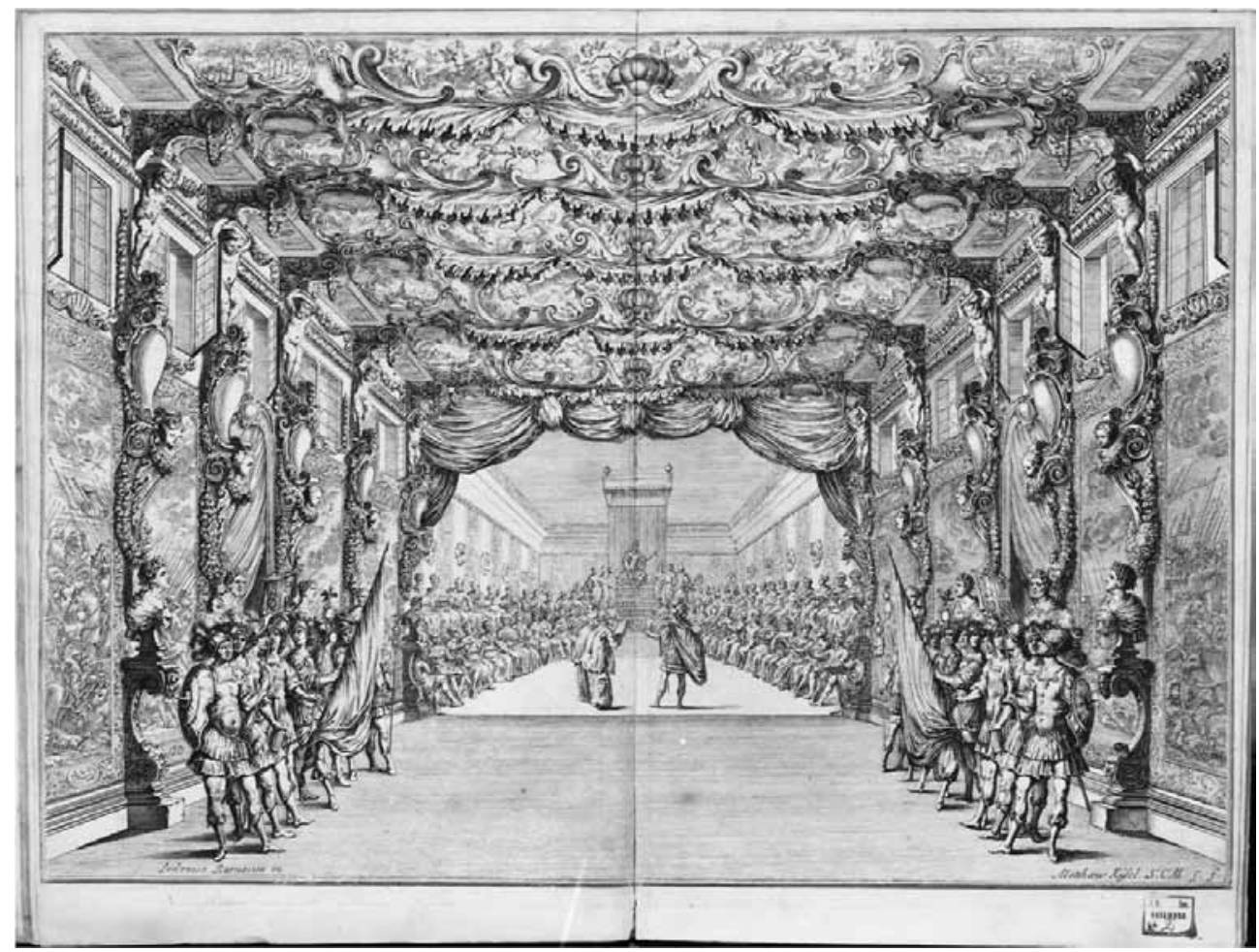

Fig. 4. Il Fuoco Eterno, 1674, Ludovico Octavio Burnacini, BNE.

leonardesco, encargado asimismo de todo el proyecto ideológico del espectáculo promocionado por señores, príncipes y monarcas absolutistas en ciernes, en cuyas manos recayó la enorme tarea de construir el entramado estructural de la retórica laudatoria a través de los programas figurativos y literarios de los aparatos de las distintas celebraciones. Como creadores, igualmente, del género apoteósico por excelencia de la ópera dramática en que culminó la Fiesta Barroca, no sólo debieron ocuparse de tales menesteres cuanto de otros tantos como la coordinación general, de las declamaciones recitativas de los actores y divos varios, e incluso de recopilar la crónica de los eventos para la imprenta, como testimonio para la posteridad. Vasari, Buontalenti, Parigi, Torelli, Tacca, Aleotti, Vigarani, Bernini, Guitti. Balbi, Santurini, Burnacini o Bibbiena fueron algunos de los apellidos más insignes de la figura del Escenógrafo de esos tiempos, y gracias a quienes se asentaron las bases de un Arte convertido en eminente profesión.

En definitiva, el propósito de esta breve aproximación a materias aparentemente tan diversas como la Cartografía y la Escenografía, es la de apostar por la flexibilidad a la hora de afrontar la Investigación del Patrimonio Artístico, desde la indagación y revisión de las Fuentes, gráficas y literarias, hasta la propia manera de abordar la Metodología desde un punto de vista ortodoxo pero elástico, que 


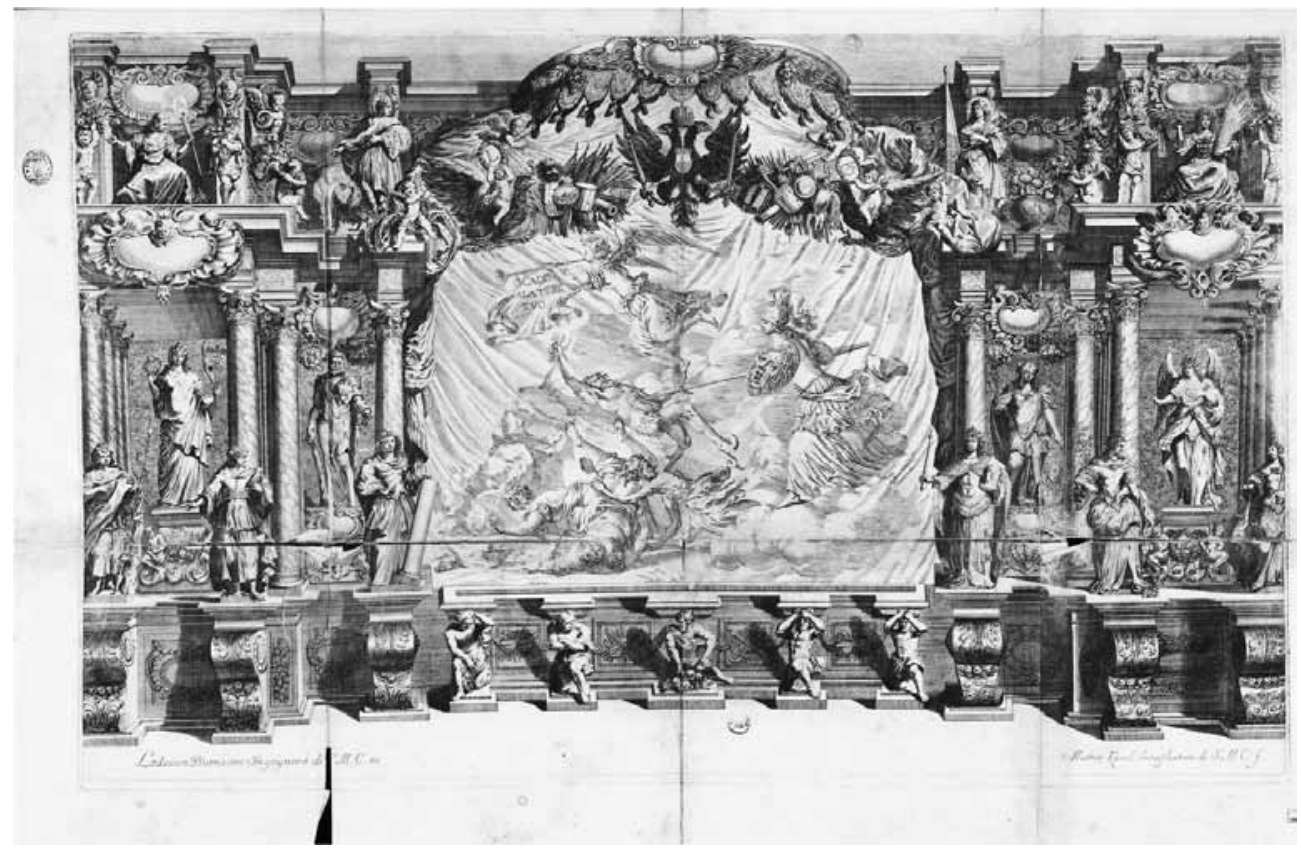

Fig. 5. Il Fuoco Eterno, 1674, Ludovico Octavio Burnacini, BNE.

pueda solventar no sólo cuestiones formales sino también abundar en el entramado semiótico de los contenidos. "Es inadmisible la conducta habitual de los historiadores, que se fatigan en probar a veces con superflua ostentación de rigor, los datos manejados, pero rehúyen plantearse las cuestiones de realidad humana que anuncian, con lo cual resulta que siendo los libros de historia los más fáciles de leer son los menos inteligibles. La Historia, al fin y al cabo, debe ser o es razón narrativa" ${ }^{10}$.

10 ORTEGA Y GASSET, J., "Sentido de las nuevas Humanidades”, en ORTEGA y GASSET, J. (1969), op cit., p. 18. 